\title{
Characteristics of Adults with Serious Psychological Distress as Measured by the K6 Scale: United States, 2001-04
}

by Laura A. Pratt, Ph.D., Office of Analysis and Epidemiology; Achintya N. Dey, M.A., Division of Health Interview Statistics; Alan J. Cohen, M.A., Office of Analysis and Epidemiology

\section{Abstract}

Objective-This report estimates the prevalence of serious psychological distress (SPD) in the noninstitutionalized adult population of the United States, as measured by the K6 scale of nonspecific psychological distress, and describes the characteristics of adults with and without SPD. These findings are compared with results from previous studies of the characteristics of adults with serious mental illnesses that cause significant disability, such as severe major depression, bipolar disorder, and schizophrenia.

Methods-The estimates in this report were derived from the Family Core and Sample Adult components of the 2001-04 National Health Interview Survey, conducted by the Centers for Disease Control and Prevention's National Center for Health Statistics (NCHS). Estimates were calculated using the SUDAAN statistical package to account for the complex survey design.

Results - The prevalence of SPD was higher among adults 45-64 years old than younger adults 18-44 years or older adults 65 years and over. Adults with SPD were more likely to be female, have less than a high school diploma, and live in poverty, and less likely to be married than adults without SPD. Moreover, those with SPD were more likely to be obese and to be current smokers. They have a higher prevalence of ever being diagnosed with heart disease, diabetes, arthritis, and stroke than persons without SPD. Adults with SPD were more likely to report needing help with activities of daily living (ADLs) and instrumental activities of daily living (IADLs). They also used more medical care services such as doctor visits and visits to mental health professionals than adults without SPD.

Conclusions-The associations between SPD and sociodemographic characteristics, health status, and health care utilization are similar to the relationships found between serious mental illnesses (for example, major depression or schizophrenia) and these same variables. Persons with SPD demonstrate disadvantage in both socioeconomic status and health outcomes.

Keywords: mental health • mental illness • National Health Interview Survey • K6

\section{Introduction}

Mental health is an important component of overall health. Mental illnesses cause suffering, disability, and, more rarely, death. Among working-age adults, mental illness is a major and expensive cause of lowered work productivity $(1,2)$. Among older adults, mental illnesses increase the risk of institutionalization (3). The World Health Organization Global Burden of Disease Study lists 4 mental illnesses among the 10 leading causes of disability worldwide, specifically, unipolar major depression, bipolar disorder, schizophrenia, and obsessivecompulsive disorder (4). The Institute of Medicine estimates that $90 \%$ of persons who commit suicide suffer from a diagnosable psychiatric disorder at the time of their deaths (5).

Accurate information about the prevalence of mental illness and characteristics of adults with mental disorders is important in planning policies for treatment and prevention, but measuring mental illness in general population surveys has many challenges. It is not possible to determine accurately whether survey respondents have particular mental illnesses by asking 
them directly because most people with mental illness do not have contact with mental health care providers and may be unaware of their diagnosis (6).

Diagnostic interviews for lay

interviewers, such as the Diagnostic Interview Schedule (DIS) (7) and the Composite International Diagnostic Interview (CIDI) (8), which are based on the Diagnostic and Statistical Manual (DSM) (9) criteria used by clinicians to make diagnoses, tend to be long and cumbersome. Surveys that measure all aspects of health cannot afford to include these instruments on anything but a sporadic basis. In an attempt to make information on mental health easier to collect in nationally representative general population surveys, Kessler and colleagues developed a scale of nonspecific psychological distress consisting of only six questions, the K6 (10).

The K6 was developed to identify persons with a high likelihood of having a diagnosable mental illness and associated functional limitations using as few questions as possible. It measures nonspecific psychological distress rather than specific mental illnesses and is intended to identify persons with mental health problems severe enough to cause moderate to serious impairment in social, occupational, or school functioning and to require treatment. Its development and psychometric properties are described elsewhere (10).

To date, the K6, or the K10-which is the K6 plus four additional distress symptom questions - has been used in general population surveys in Australia, Canada, the United States, and as part of the World Health Organization's World Mental Health Surveys, in 30 other countries worldwide (11). Since 1997, the K6 has been part of the National Health Interview Survey (NHIS), conducted by NCHS (12). The K6 has also been included on the Medical Expenditure Panel Survey (MEPS) since 2004. The MEPS is conducted by the Agency for Healthcare Research and Quality (AHRQ) (13) and follows a subsample of NHIS respondents. A modified version of the K6 has been used in the National Household Survey on Drug Use and Health (NSDUH), conducted by the
Substance Abuse and Mental Health Services Administration (SAMHSA) (14) since 2001.

Researchers have also begun to use the K6 in contexts other than large, nationally representative surveys. For example, some state-based surveys of Temporary Assistance for Needy Families (TANF) recipients have used the K6 to screen for mental disorders (15). Another investigator has suggested its use to screen criminal justice populations for mental illness (16). Translations of the K6/K10 associated with the World Mental Health Survey Initiative led to its use in non-Englishspeaking countries. As the K6 is used more widely and in different contexts, the importance of understanding what it measures increases.

This report uses the 2001-04 NHIS to describe the characteristics of adults with K6-measured SPD and to compare these findings with results of previous studies of the characteristics of persons with serious mental illnesses that cause impairment in role functioning, such as severe major depression, bipolar disorder, and schizophrenia, in the noninstitutionalized population.

\section{Methods}

\section{Data source}

The NHIS is a continuous face-toface household interview survey that covers a wide variety of health-related topics. It is a complex, stratified sample survey designed to provide estimates for the civilian noninstitutionalized population of the United States. Every year data are collected about all family members in approximately 40,000 households. More detailed health information is obtained from one randomly sampled adult (the "sample adult") and one randomly sampled child in each family in the sample. The present study uses data from the combined 2001 through 2004 sample adult interviews for a total of 123,610 persons 18 years of age and older living in the community. Three variables from the family questionnaire are also analyzed. The final response rate for the 2001-04 combined household files was $88.6 \%$ and for sample adult files was
$73.7 \%$. Data from the sample adult questionnaire are self-reported, except when respondents are physically incapable of responding for themselves. This study includes proxy-reported data for 931 sample persons, self-reported data for 122,591 sample persons, and 88 sample persons without data on respondent status.

\section{Measurement of SPD}

The K6 asks about the frequency of each of six symptoms of mental illness or nonspecific psychological distress:

During the PAST 30 DAYS, how often did you feel...

1. So sad that nothing could cheer you up;

2. Nervous;

3. Restless or fidgety;

4. Hopeless;

5. That everything was an effort; and

6. Worthless.

The following options are given for describing frequency:

1. ALL of the time;

2. MOST of the time;

3. SOME of the time;

4. A LITTLE of the time; and

5. NONE of the time.

"None of the time" is given a score of 0 , "all of the time" a score of 4 and the total possible score ranges from 0 to 24. As suggested by Kessler and colleagues (17), a score of 13 or above is used to indicate serious psychological distress. The prevalence rates presented here are described as 30-day prevalence rates because the reference period for the symptom questions is the "past 30 days."

The first validity study using the K6 was done by Kessler and colleagues (18) with the modified NSDUH version. That version of the K6 asks about the same symptoms and uses the same scoring but has a modified stem question that asks respondents how frequently they experienced symptoms of psychological distress "during the 1 month in the past year when they were at their worst emotionally." That version was tested along with two other instruments, a greatly abbreviated set of the Composite International Diagnostic 
Interview (CIDI) questions (19) and the World Health Organization Disability Assessment Scale (WHO-DAS) (20), and determined to have the best sensitivity and specificity of the three for DSM disorders as measured by the Structured Clinical Interview for DSM-IV (SCID) administered by mental health professionals (18). Validity studies using the original "past 30 days" stem question are in progress (21).

\section{Measurement of other variables}

Other variables available from the NHIS and used in these analyses include sociodemographic characteristics such as sex, age, race and ethnicity, marital status, family income, and education. Family size and family income are used to define three economic categories: poor, living below the federal poverty line; near poor, 100 to less than $200 \%$ of the federal poverty line; and not poor, living at or above $200 \%$ of the federal poverty line.

Indicators of access to health care include health insurance status at the time of interview for persons under 65 years of age and unmet need for health care due to cost in the past 12 months. Measurements of health care utilization include how long it has been since a respondent saw a doctor, how many doctor visits a respondent has had in the last 12 months, and whether the person has spoken to a mental health professional in the last year.

Risk factors and health status measures include smoking, body mass index (BMI), and the presence or absence of seven chronic physical illnesses, all self-reported in the sample adult interview. Smoking status is categorized as current, former, and never smoker. BMI was calculated using self-reported height and weight and categorized as underweight (BMI less than 18.5), normal weight (BMI greater than or equal to 18.5 but less than 25), overweight (BMI greater than or equal to 25 but less than 30), and obese (BMI greater than or equal to 30). The sample adult is asked about the following chronic diseases: chronic lung disease, heart disease, diabetes, hypertension, arthritis, cancer, and stroke. The questions ask if a doctor has ever told the respondent that he or she had the disease.

Functional limitations are measured by any report of needing help in one of four ADLs_ - eating, bathing, dressing, or getting around inside the house, and four IADLs-everyday household chores, doing necessary business, shopping, or getting around for other purposes. Physical limitations are measured by difficulty walking onefourth of a mile and difficulty climbing a flight of steps.

Difficulties in social functioning are evaluated by three questions in the NHIS. They include difficulty in participating in outside activities like shopping or attending movies or sporting events; participating in social activities such as visiting friends, attending clubs and meetings, or going to parties; and doing things to relax at home or for leisure (reading, watching $\mathrm{TV}$, sewing, listening to music ...).

\section{Statistical analysis}

First, the prevalence of SPD among persons with selected characteristics is described. Crude prevalence rates are shown for each characteristic.

Next, characteristics of persons with and without SPD are compared and associations described. To remove the effect of any differences in the age distributions of the two groups, the rates are age adjusted to the year 2000 standard projected U.S. population using five age groups: 18-44 years, 45-54 years, 55-64 years, 65-74 years, and 75 years and over. Percent distributions and standard errors are presented. The statistical significance of differences between estimates was evaluated using two-sided $t$-tests. These tests did not formally take multiple comparisons into account, but because of the large number of tests carried out, the 0.01 level rather than the 0.05 level was used for significance testing. Differences discussed in the text were statistically significant at the $p<0.01$ level. When a difference is not described in the text, it does not necessarily mean that a $t$-test was performed and the difference was found to be not significant.
Because of the large number of respondents missing family income information, approximately one-third of respondents, the analyses that include poverty status and income use multiply imputed family income (22). The results of these analyses are similar to the results that use only the two-thirds with reported family income. SUDAAN is used for all analyses to account for the complex, clustered sample design of the NHIS (23).

\section{Results}

\section{Prevalence of SPD}

The crude 30-day prevalence rate of SPD in the noninstitutionalized adult population of the United States was $3.1 \%$ over the 4 years from 2001-04 (Table 1). The prevalence was highest in middle-aged adults 35-64 years old, lower in younger adults, and lowest in adults 65 years of age and over. The 1-month prevalence rate of SPD was higher in women $(3.9 \%)$ than men $(2.4 \%)$ overall and in every age group, although the difference did not reach statistical significance in persons 65-74 years of age (Figure 1). Persons living below the poverty line had a prevalence rate of $8 \%$, four times as high as that of persons with family income at $200 \%$ of the poverty line or higher $(2 \%)$.

Hispanic adults aged 65 years and over had a higher prevalence of SPD $(5.9 \%)$ than did non-Hispanic white adults $(2.1 \%)$ or non-Hispanic black adults $(2.4 \%)$ in the same age group (Figure 2). In contrast, there was no significant difference in prevalence rates of SPD by race and ethnicity among adults 18-44 years old. Among Hispanic adults, the prevalence of SPD was lower $(2.7 \%)$ in persons aged 18-44 years

(Figure 2) than in persons aged 45-64 years $(5 \%)$ or persons 65 years of age and over, while among non-Hispanic white adults, the prevalence of SPD in persons 65 years of age and over $(2.1 \%)$ was the lowest of any age group.

In each race and ethnicity group, the prevalence of SPD was much higher among poor respondents (those living below the federal poverty threshold) than among those at higher incomes (Figure 3). The prevalence of SPD 


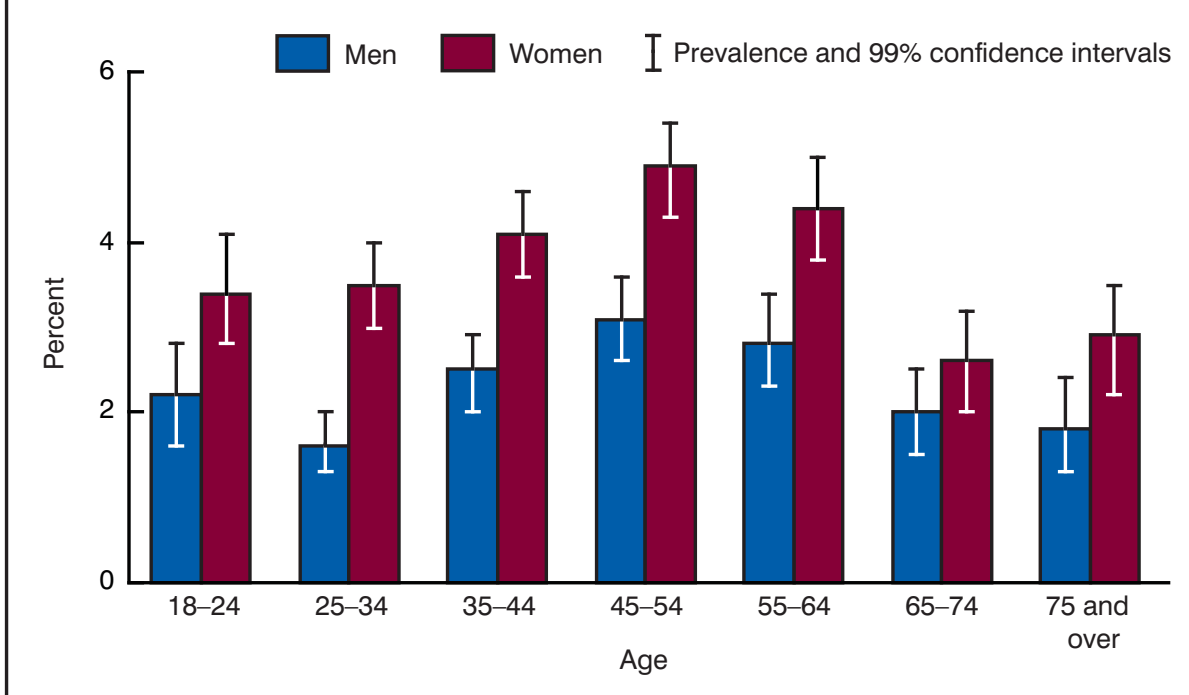

DATA SOURCE: National Health Interview Survey, 2001-04. Data are based on household interviews of a sample of the civilian noninstitutionalized population.

Figure 1. Crude 30-day prevalence of serious psychological distress by age and sex, National Health Interview Survey 2001-04

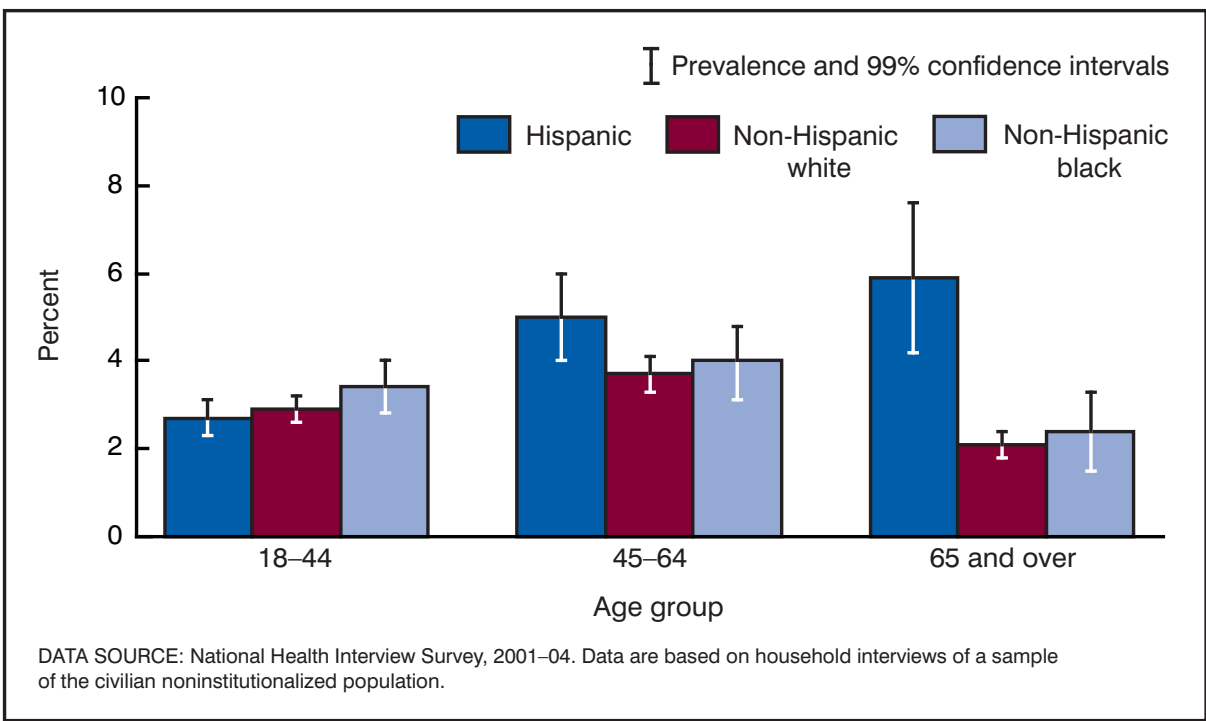

Figure 2. Crude 30-day prevalence of serious psychological distress by race or ethnicity and age, National Health Interview Survey 2001-04

among poor non-Hispanic white adults $(9.2 \%)$ was higher than among poor Hispanic adults (6.4\%). Among not poor respondents (those living at $200 \%$ of the poverty threshold or higher), there was no significant difference in the prevalence of SPD among non-Hispanic blacks (1.6\%), non-Hispanic whites $(1.9 \%)$, or Hispanics $(2.1 \%)$.
(34\%) than adults without SPD (17\%), and much less likely to have received a college degree (9\%) than adults without SPD (25\%). Forty-four percent of persons with SPD had a family income of less than $\$ 20,000$ per year, while only $20 \%$ of persons without SPD had this level of income. Persons with SPD were less likely to live with other family members $(76 \%)$ than were persons without SPD (81\%). They were also twice as likely to be divorced (24\% versus $12 \%$ ). Persons with SPD were slightly more likely to live in rural areas (nonmetropolitan statistical areas) than persons without SPD.

\section{Health status and health behaviors}

In age-adjusted comparisons, almost one-half of persons with SPD had fair or poor health, while only $11 \%$ of persons without SPD had fair or poor health (Table 3). Persons with SPD were at least twice as likely to have ever been diagnosed with heart (14\%) or lung disease (24\%), diabetes (13\%), arthritis $(40 \%)$, or stroke $(8 \%)$ than were persons without SPD. They were also twice as likely to have two or more of the seven selected chronic diseases $(35 \%$ compared with $17 \%$ ).

Forty-two percent of persons with SPD were current cigarette smokers as compared with $21 \%$ of persons without SPD. They were also more likely to be obese (33\% compared with $23 \%$ ).

\section{Access to and utilization of health care services}

Persons with SPD were much more likely to forgo needed health care because of cost (Table 4). For example, $18 \%$ of persons with SPD needed mental health care but were not able to afford it, while only $2 \%$ of persons without SPD had this problem. This difference may be due to both greater need for care as well as less access to care among those with SPD. Persons with SPD were more likely to need dental care and be unable to afford it (32\%), and they were more likely to be unable to get needed prescription drugs because of cost (32\%) than were persons without SPD (10\% and 7\% respectively). Persons with SPD were more than four times as likely to have 


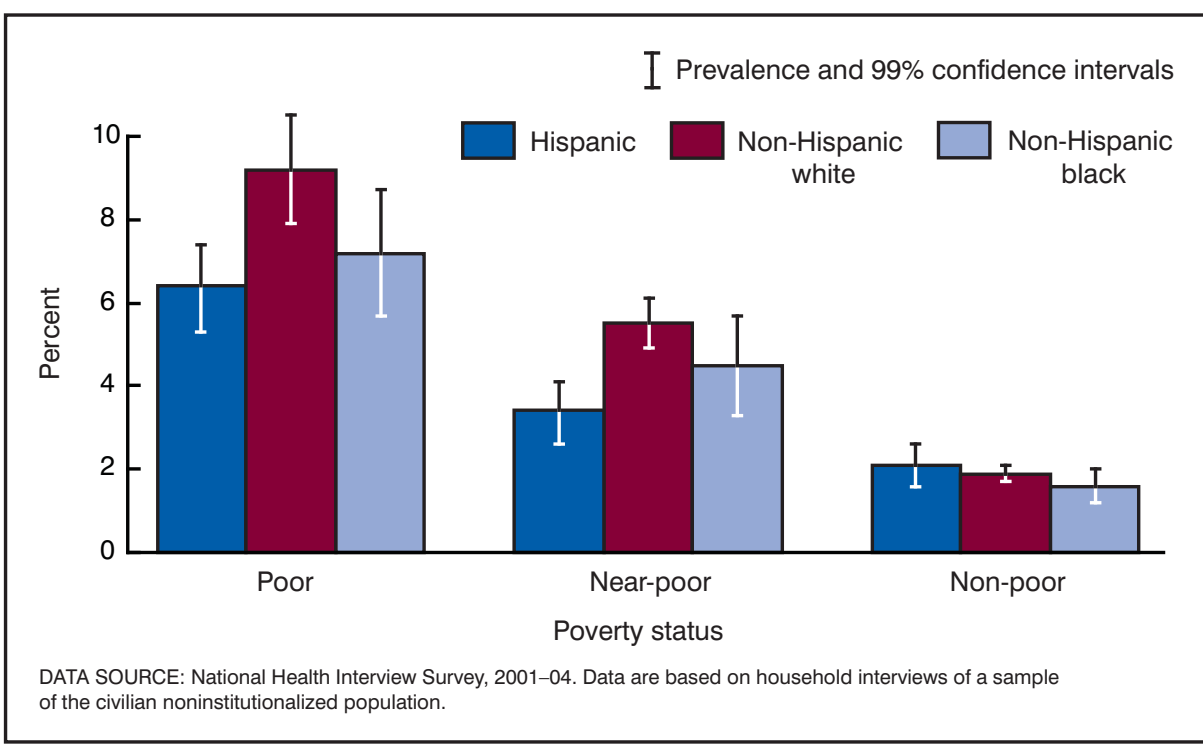

Figure 3. Age-adjusted 30-day prevalence of serious psychological distress by race or ethnicity and poverty, National Health Interview Survey, 2001-04

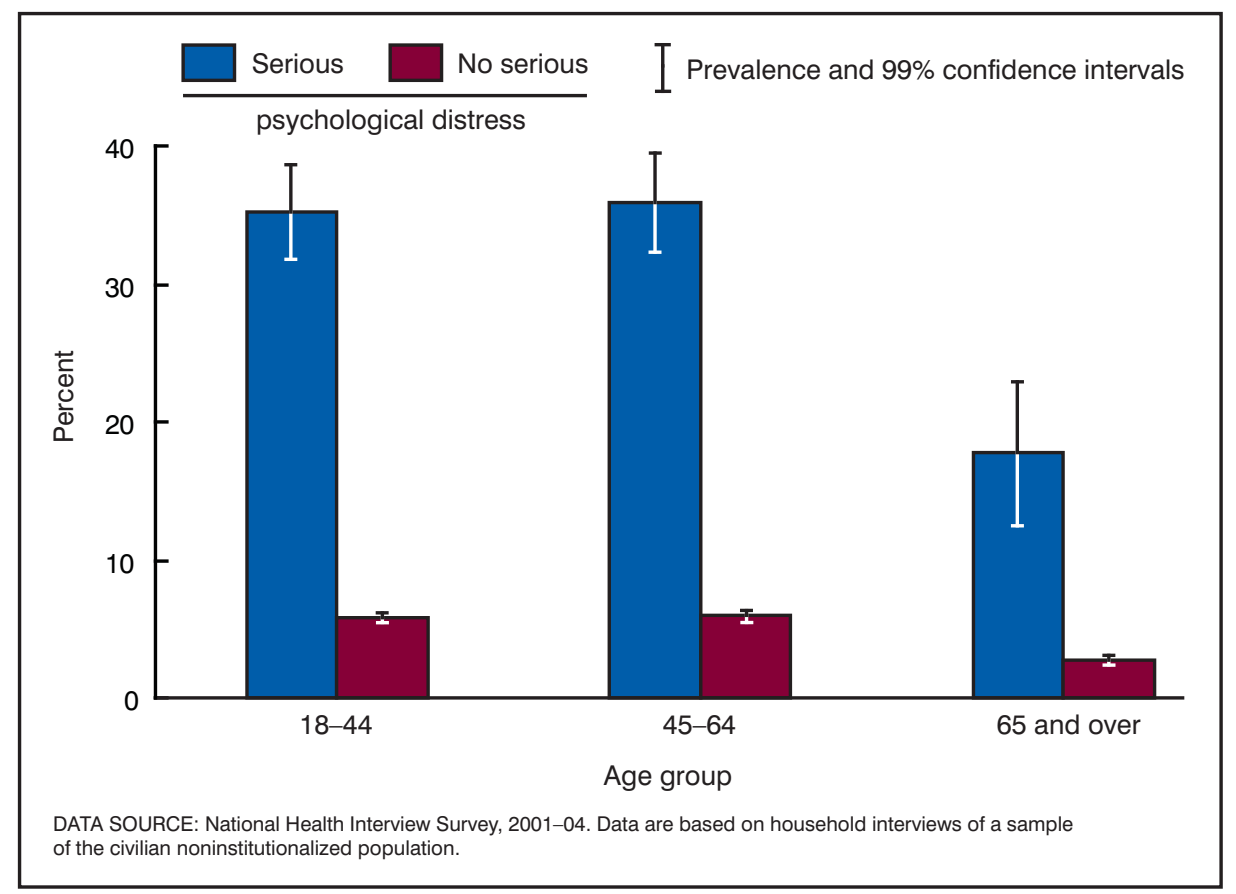

Figure 4. Percent reporting any contact with mental health professional by serious psychological distress and age, National Health Interview Survey, 2001-04

Medicaid as were persons without SPD, $25 \%$ and $6 \%$, respectively. They were also significantly more likely to be uninsured (29\% compared with 19\%) than those without SPD.

Persons with SPD are heavy utilizers of medical care, consistent with their poorer health status. They were more likely to have seen a health care professional within the last 6 months $(81 \%)$ than persons without SPD $(69 \%)$ and were three times as likely to have had 10 or more visits within the past year (39\% compared with 13\%).

Thirty-two percent of persons with SPD talked to a mental health professional within the year prior to the interview, substantially more than the $5 \%$ of those without SPD. Among adults with SPD, those over the age of 65 were least likely to have seen a mental health professional: $18 \%$ had such contact.
Among adults younger than 65 who had SPD, $36 \%$ spoke to a mental health professional within the past 12 months (Figure 4).

\section{Functional limitations}

Persons with SPD were more likely to have functional limitations than persons without SPD (Table 5). Persons with SPD were more than six times as likely to need help with ADLs (9\%) and IADLs (19\%) than were persons without SPD (1\% and $3 \%)$. They were also more likely to have vision $(27 \%)$ and hearing impairment (8\%) than persons without SPD (9\% and 3\%). A larger proportion of persons with SPD had difficulty walking (41\%) and difficulty climbing a flight of stairs (35\%) than did persons without SPD (10\% and 7\%). Thirty-four percent of persons with SPD had difficulty getting out to go shopping, to the movies, or other events, and $32 \%$ of persons with SPD had difficulty in social activities compared with less than $5 \%$ of persons without SPD. Eighteen percent of persons with SPD had difficulty with relaxing at home by reading, watching $\mathrm{TV}$, or listening to music compared with less than $2 \%$ of persons without SPD.

\section{Comparisons of the characteristics of persons with SPD and persons with serious mental illness}

The Surgeon General's Report on Mental Health defines serious mental illness as mental illness that causes significant disability. Included in the category of serious mental illness in the Surgeon General's Report are schizophrenia, bipolar disorder, obsessive-compulsive disorder (OCD), panic disorder, and severe forms of major depression (3). The report estimates that $5.4 \%$ of American adults have a serious mental illness in any one year and that about one-half of the 5.4\% have a serious and persistent mental illness, generally lifelong conditions. The 1-month prevalence rate for SPD in the 2001-04 NHIS of 3.1\% is not inconsistent with these estimates.

As measured by the K6 scale in the 2001-04 NHIS, women have a higher prevalence of SPD than men in every 
age group. Most studies agree that the prevalence of schizophrenia and bipolar disorder is the same in men and women $(24,25)$, while major depression is two to three times as common in women as in men (26). OCD is equally common in women and men, but other anxiety disorders such as panic disorder and generalized anxiety disorder are more common in women (3).

In the 2001-04 NHIS, Hispanic adults 65 years and over had higher rates of SPD than non-Hispanics of the same age. The prevalence rate of SPD in Hispanics 18-44 years of age was similar to that in non-Hispanic white and non-Hispanic black persons (Figure 2). In the 1996 Health and Retirement Survey (HRS), Hispanic persons aged 54-65 years had higher rates of major depression as measured by the CIDI-SF than did non-Hispanic white persons (27). Other studies of the relationship between Hispanic ethnicity and prevalence of various mental illnesses have found lower rates among Hispanics than other ethnic groups (28-32), but age-stratified results were not presented.

Persons with SPD demonstrated social disadvantage in the 2001-04 NHIS. Persons with SPD were more likely to be poor (live below the federal poverty line) than persons without SPD. Persons with SPD were much less likely to be married or have finished their high school education than persons without SPD. The higher rate of poverty among seriously mentally ill persons is a common finding (33-34). In a series of three papers describing the social consequences of psychiatric illness, Kessler and colleagues (35-37) demonstrated that early-onset psychiatric illness is associated with lower educational achievement, higher risk of teenage pregnancy, and inability to find or maintain a relationship leading to marriage.

Persons with SPD in the 2001-04 NHIS were more likely to have poor health and to smoke. Many studies have reported a relationship between mental illness, especially major depression and schizophrenia, and many chronic diseases, particularly cardiovascular disease (38-42). The finding that persons with mental illnesses are more likely to smoke has been reported many times with many different mental illnesses (43-44).

Persons with SPD had more recent and more frequent interaction with health care professionals than persons without SPD. Persons with mental illness have consistently been found to be high utilizers of medical care. There is a large amount of literature documenting this association, especially among persons with depression (45-48).

In the 2001-04 NHIS, only $32 \%$ of persons with SPD had contact with a mental health professional in the previous year. A single report of contact with a mental health professional provides no information on whether a patient was treated, treated appropriately, and able to comply with treatment. Low levels of treatment have also been reported in other studies. In the Epidemiologic Catchment Area Program (ECA) surveys, which took place between 1981 and 1984, researchers found that only one-third of persons with mental disorders received treatment (49). In the National Comorbidity Survey (NCS) of the early 1990s, reported treatment rates were also approximately $33 \%$ (50). In the NCS Replication, fielded from 2001 to 2003 , researchers found a slightly higher percent receiving treatment, $41 \%$, but found that only one-third of persons with a disorder who received treatment received "minimally adequate treatment" (51).

Persons with SPD in the 2001-04 NHIS had high levels of functional impairment. High levels of functional limitations among persons with mental illness are a consistent finding (52-55). Symptoms of serious mental illnesses can directly cause social disability. For example, inability to concentrate is a symptom of major depression, and in severe cases, the concentration required to read a book or even to follow a television show is impossible. Persons with untreated OCD may find themselves unable to leave home because of their checking behavior, such as continuously checking to be sure the stove is off or continuously checking the door to be sure it is locked. The symptoms of all the serious mental illnesses, including schizophrenia, bipolar disorder, severe forms of major depression, and OCD, are not conducive to forming and maintaining social relationships. The cross-sectional relationship of mental illness with physical limitations in functioning has also been reported in other studies (56, 57).

\section{Discussion}

The characteristics of persons with SPD as measured by the K6 are the same as the characteristics of persons with serious mental illnesses as described in psychiatric epidemiologic studies. The associations of SPD with age, marital status, education, and income are all in the expected direction. In accord with what we know about the epidemiology of serious mental illness in the general population, K6-measured SPD is associated with high levels of functional limitations and high utilization of medical care. As seen in other studies of mental illness, only onethird of persons with SPD have seen a mental health professional in the past year, an area that deserves further investigation. This study found higher rates of SPD in older Hispanic persons than in other older adults. Replication of this finding in studies using diagnosisbased measures of mental illness would be valuable in planning targeted interventions.

Because of the cross-sectional design of the NHIS, the direction of causation of the associations described in this report cannot be inferred from these data. Prospective studies that measure the $\mathrm{K} 6$ in respondents at baseline and then follow the respondents over time are needed to clarify the temporal relationships. The Medical Expenditure Panel Survey (MEPS) follows a subsample of NHIS participants for another 2 years, providing 3 years of data on persons in the subsample. The MEPS provides the opportunity to explore some relationships, particularly between serious psychological distress and health care utilization, but the follow-up period is too short to clarify the temporal associations between SPD and chronic illnesses or functional limitations. 
A major limitation of the K6 is that it does not provide information on which particular psychiatric diagnosis or diagnoses a respondent may have. Since 1980, psychiatric epidemiology has concentrated on diagnostic interviews for general population surveys, so using the information provided by the K6 requires a paradigm switch. Although our study documents that SPD measured by the $\mathrm{K} 6$ is related to other covariates in a similar manner to serious mental illnesses, it remains difficult to identify what is being measured. The particular symptoms included in the $\mathrm{K} 6$ as well as the gender disparity observed makes it likely that severe, disabling mood and anxiety disorders are being identified. It is less clear whether persons with schizophrenia, the most serious mental illness, are identified.

In the lay-person interviews used in psychiatric epidemiologic surveys, such as the DIS and the CIDI, respondents answer questions about their own symptomatology. For reasons probably related to the diseases themselves, respondents with psychosis and mania may not accurately assess or report whether they have the symptoms (58-60). It is unclear whether the K6 is any more successful at capturing persons with these disorders. Since the K6 asks about symptoms of distress rather than particular symptoms of the illnesses, such as psychosis, it is possible that the K6 may identify persons with schizophrenia or bipolar disorder as having SPD. In addition, we do not know how many persons identified by the K6 have disabling mental health problems that might not fit into any of the diagnostic categories described in the DSM. As results from validation studies related to the World Mental Health Surveys Initiative become available, the diagnostic characteristics of persons with SPD will be clarified.

One limitation of this study is that many people with the most serious mental illnesses are either homeless or institutionalized, and because the NHIS is a household survey, these people are not surveyed. Another limitation, shared by all symptom count measures, is that persons with serious mental illness who are being treated successfully will not be captured by the K6.
A major strength of the K6 lies in its brevity. It is short enough that it is feasible to add to lengthy, general health interviews like the NHIS. As more researchers use the K6 scale in studies using the data from the MEPS and the NSDUH, as well as the NHIS, more will be learned about its properties and usefulness.

\section{References}

1. Wu EQ, Birnbaum HG, Shi L, Ball DE, Kessler RC, Moulis M, Aggarwal J. The economic burden of schizophrenia in the United States in 2002. J Clinical Psychiatry 66:11229. 2005.

2. Greenberg PE, Birnbaum HG. The economic burden of depression in the U.S.: Societal and patient perspectives. Expert Opinion on Pharmacotherapy 6(3):369-76. 2005.

3. Surgeon General's Office. Mental Health: A Report of the Surgeon General. United States Public Health Service, Washington, DC. 1999.

4. Lopez AD, Murray CCJL. The global burden of disease, 1990-2020.

Nature Medicine 4(11):1241-3. 1998.

5. Institute of Medicine. Reducing Suicide: A National Imperative. National Academies Press, Washington, DC. 2002.

6. Wang PS, Berglund P, Olfson M, Pincus HA, Wells KB, Kessler RC. Failure and delay in initial treatment contact after first onset of mental disorders in the National Comorbidity Survey Replication. Arch Gen Psychiatry 62:603-13. 2005.

7. Robins LN, Helzer JE, Croughan J, Ratcliff KS. National Institute of Mental Health Diagnostic Interview Schedule. Its history, characteristics, and validity. Arch Gen Psychiatry 38:381-9. 1981.

8. Robins LN, Wing J, Wittchen HU, Helzer JE, Babor TF, Burke J, et al. The Composite International Diagnostic Interview. An epidemiologic instrument suitable for use in conjunction with different diagnostic systems and in different cultures. Arch Gen Psychiatry 45:1069-77. 1988.

9. American Psychiatric Association, 2000. Diagnostic and Statistical Manual of Mental Disorders, Fourth Edition. American Psychiatric Association: Washington, DC.
10. Kessler RC, Andrews G, Colpe LJ, Hiripi E, Mroczek DK, Normand SLT, Walters EE, Zaslavsky AM. Short screening scales to monitor population prevalences and trends in non-specific psychological distress. Psychological Medicine 32:959-76. 2002.

11. Kessler RC, Ustun TB. The World Mental Health (WMH) Survey Initiative version of the World Health Organization (WHO) Composite International Diagnostic Interview (CIDI). Int J Methods Psychiatr Res 13:93-121. 2004.

12. National Center for Health Statistics. National Health Interview Survey, 2001-04. http://www.cdc.gov/nchs/ nhis.htm.

13. Agency for Healthcare Research and Quality. Medical Expenditure Panel Survey (MEPS). http:// www.meps.ahrq.gov/.

14. Substance Abuse and Mental Health Services Administration. National Survey on Drug Use and Health (NSDUH). http://oas.samhsa.gov/ nsduh.htm.

15. Assistant Secretary for Planning and Evaluation. U.S. Department of Health and Human Services. Families on TANF in Illinois: Employment Assets and Liabilities. June 10, 2003. Available at http://aspe.hhs.gov/hsp/ TANF-IL-emp03/index.htm. Accessed May 30, 2006.

16. Swartz J. Screening for serious mental illness among offenders. Illinois Criminal Justice Information Authority: Research Bulletin 4(5). 2005. Available at http:// www.icjia.state.il.us/public/pdf/ Bulletins/mental\%20illness.pdf. Accessed May 30, 2006.

17. Kessler RC, Berglund PA, Glantz MD, Koretz DS, Merikangas KR, Walters EE, Zaslavsky AM. Estimating the prevalence and correlates of serious mental illness in community epidemiological surveys. In: Manderscheid RW, Henderson MJ, eds. Mental Health, United States, 2002. Rockville, Maryland: U.S. Department of Health and Human Services 155-64. 2004.

18. Kessler RC, Barker PR, Colpe LJ, Epstein JF, Gfroerer JC, Hiripi E, Howes MJ, Normand SL, Manderscheid RW, Walters EE, Zaslavsky AM. Screening for serious mental illness in the general population. Arch Gen Psychiatry 60:184-9. 2003. 
19. Kessler RC, Andrews G, Mroczek D, Ustun TB, Wittchen H-U. The World Health Organization Composite International Diagnostic Interview Short-Form (CIDI-SF). Int J Methods Psychiatr Res 7:171-85. 1998.

20. Rehm J, Ustun TB, Saxena S, Nelson CB, Chatterji S, Ivis F, Adlaf E. On the development and psychometric testing of the WHO screening instrument to assess disablement in the general population. Int J Methods Psychiatr Res 8:110-23. 1999.

21. National Comorbidity Survey: K10 and K6 scales. http:// www.hcp.med.harvard.edu/ncs/ k6_scales.php. Accessed May 30, 2006.

22. Schenker N, Raghunathan TE, Chiu P-L, Makuc DM, Zhang G, Cohen AJ. Multiple imputation of family income and personal earnings in National Health Interview Survey: methods and examples. January 18, 2006. Available at www.cdc.gov/ nchs/data/nhis/tecdoc.pdf.

23. Research Triangle Institute. SUDAAN, Release 9.0. Research Triangle Park, NC: Research Triangle Institute. 2002.

24. Hambrecht M, Riecher-Rossler A, Fatkenheuer B, Louza MR, Hafner H. Higher morbidity risk for schizophrenia in males: Fact or fiction? Comprehensive Psychiatry 35(1):39-49. 1994.

25. Grant BF, Stinson FS, Hasin DS, Dawson DA, Chou SP, Ruan WJ, Huang B. Prevalence, correlates, and comorbidity of bipolar I disorder and axis I and II disorders: Results from the National Epidemiologic Survey on Alcohol and Related Conditions J Clin Psychiatry 66(10):1205-15. 2005.

26. Weissman MM, Leaf PJ, Tischler GL, Blazer DG, Karno M, Bruce ML, Florio LP. Affective disorders in five United States communities. Psychological Medicine 18:141-53. 1988.

27. Dunlop DD, Song J, Lyons JS, Manheim LM, Chang RW. Racial/ ethnic differences in rates of depression among preretirement adults. AJPH 93:1945-52. 2003.

28. Breslau J, Aguilar-Gaxiola S, Kendler KS, Su M, Williams D, Kessler RC. Specifying race-ethnic differences in risk for psychiatric disorder in a USA national sample. Psychological Medicine 36:57-68. 2006.
29. Hernandez A, Plant EA, SachsEricsson N, Joiner TE. Mental health among Hispanics and Caucasians: Risk and protective factors contributing to prevalence rates of psychiatric disorders. Anxiety Disorders 19:844-60. 2005.

30. Ortega AN, Rosenheck R, Alegria M, Desai RA. Acculturation and the lifetime risk of psychiatric and substance use disorders among Hispanics. J of Nervous and Mental Disease 188(11):728-35. 2000.

31. Grant BF, Hasin DS, Stinson FS, Dawson DA, Ruan WJ, Goldstein RB, Smith SM, Saha TD, Huang B. Prevalence, correlates, comorbidity, and comparative disability of DSM-IV generalized anxiety disorder in the USA: Results from the National Epidemiologic Survey on Alcohol and Related Conditions. Psychological Medicine 35:1-13. 2005.

32. Hasin DS, Goodwin RD, Stinson FS, Grant BF. Epidemiology of major depressive disorder: Results from the National Epidemiologic Survey on Alcohol and Related Conditions. Archives of General Psychiatry 62:1097-1106. 2005.

33. Faris REL, Dunham FW. Mental disorders in urban areas; an ecological study of schizophrenia and other psychoses. Chicago University Press. Chicago. 1939.

34. Regier DA, Farmer ME, Rae DS, Myers JK, Kramer M, Robins LN, George LK, Karno M, Locke BZ. One-month prevalence of mental disorders in the United States and sociodemographic characteristics: The Epidemiologic Catchment Area study. Acta Psychiatrica Scandinavica 88:35-47. 1993.

35. Kessler RC, Foster CL, Sunders WB, Stang PE. Social consequences of psychiatric disorders, I: Educational attainment. Am J Psychiatry 152(7):1026-32. 1995.

36. Kessler RC, Berglund PA, Foster CL, Sunders WB, Stang PE, Walters EE. Social consequences of psychiatric disorders, II: Teenage parenthood. Am J Psychiatry 154(10):1405-11. 1997.

37. Kessler RC, Walters EE, Forthofer MS. Social consequences of psychiatric disorders, III: Probability of marital stability. Am J Psychiatry 155(8):1092-96. 1998.

38. Glassman AH, Shapiro PA. Depression and the course of coronary artery disease. Am J Psychiatry 155:4-11. 1998.

39. Goff DC, Cather C, Evins AE, Henderson DC, Freudenreich O, Copeland PM, Bierer M, Duckworth K, Sacks FM. Medical morbidity and mortality in schizophrenia: Guidelines for psychiatrists. J Clin Psychiatry 66:183-94. 2005.

40. Harris EC, Barraclough B. Excess mortality of mental disorder. British $\mathrm{J}$ Psychiatry 173(7):11-53. 1998.

41. Hennekens CH, Hennekens AR, Hollar D, Casey DE. Schizophrenia and increase risks of cardiovascular disease. Am Heart J 150:1115-21. 2005.

42. Pratt LA, Ford DE, Crum, RM, Armenian HK, Gallo JJ, Eaton WW. Depression, psychotropic medication, and risk of myocardial infarction: Prospective data from the Baltimore ECA Follow-up. Circulation 94:3123-9. 1996.

43. Breslau N, Kilbey M, Andreski P. Nicotine dependence, major depression, and anxiety in young adults. Arch Gen Psychiatry 48:1069-74. 1991.

44. Glassman AH. Cigarette smoking: Implications for psychiatric illness. Am J Psychiatry 150:546-53. 1993.

45. Daumit GL, Pratt LA, Crum RM, Powe NR, Ford DE. Characteristics of primary care visits for individuals with severe mental illness in a national sample. General Hospital Psychiatry 24(6):391-5. 2002.

46. Egede LE, Zheng D, Simpson K. Comorbid depression is associated with increased health care use and expenditures in individuals with diabetes. Diabetes Care 25(3):46470. 2002.

47. Himelhoch S, Weller WE, Wu AW, Anderson GF, Cooper LA. Chronic medical illness, depression, and use of acute medical services among Medicare beneficiaries. Medical Care 42:512-21.

48. Pearson SD, Katzelnick DJ, Simon GE, Manning WG, Helstad CP, Henk HJ. Depression among high utilizers of medical care. J Gen Intern Med 14:461-8. 1999.

49. Regier DA, Narrow WE, Rae DS, Manderscheid RW, Locke BZ, Goodwin FK. The de facto U.S. mental and addictive disorders service system. Epidemiologic Catchment Area prospective 1-year prevalence rates of disorders and 
services. Arch Gen Psychiatry 50(2):85-94. 1993.

50. Kessler RC, Frank RG, Edlund M, Katz SF, Lin E, Leaf P. Differences in the use of psychiatric outpatient services between the United States and Ontario. NEJM 336:551-7. 1997.

51. Wang PS, Lane M, Olfson M, Pincus HA, Wells KB, Kessler RC. Twelvemonth use of mental health services in the United States: Results from the National Comorbidity Survey Replication. Arch Gen Psychiatry 62:629-40. 2005.

52. Wells KB, Stewart A, Hays RD, Burnam MA, Rogers W, Daniels M, Berry S, Greenfield S, Ware J. The functioning and well-being of depressed patients: Results from the Medical Outcomes Study. JAMA 262:914-9. 1989.

53. Broadhead WE, Blazer DG, George LK, Tse CK. Depression, disability days, and days lost from work in a prospective epidemiologic survey. JAMA, 264:2524-28. 1990.

54. Yang Y, George LK. Functional disability, disability transitions, and depressive symptoms in late life. J Aging Health 17:263-92. 2005.

55. Dunlop DD, Manheim LM, Song J, Lyons JS, Chang RW. Incidence of disability among preretirement adults: The impact of depression. AJPH 95:2003-8. 2005.

56. Penninx BWJH, Leveille S, Ferrucci L, van Eijk, J, Guralnik JM. Exploring the effect of depression on physical disability: Longitudinal evidence from the Established Populations for Epidemiologic Studies of the Elderly. AJPH 89:1346-52. 1999.

57. Lenze EJ, Rogers JC, Martire LM, Mulsant BH, Rollman BL, Dew MA, Schulz R, Reynolds CF. The association of late-life depression and anxiety with physical disability-A review of the literature and prospectus for future research. Am J Geriatr Psychiatry 9:113-5. 2001.

58. Pulver AE, Carpenter WT. Lifetime psychotic symptoms assessed with the DIS. Schizophrenia Bulletin 9:377-82. 1983.

59. Wittchen H-U, Semler G, von Zerssen D. A comparison of two diagnostic methods: Clinical ICD diagnoses vs. DSM-III and Research Diagnostic Criteria using the Diagnostic Interview Schedule (Version 2). Arch Gen Psychiatry 42:677-84. 1985.
60. Andrews G. Case ascertainment: The Composite International Diagnostic Interview. Australia New Zealand J Psychiatry 34:S161-3. 2000.

61. National Center for Health Statistics. 2001 National Health Interview Survey (NHIS). Public-Use Data Release. NHIS Survey Description (ftp://ftp.cdc.gov/pub/ Health_Statistics/NCHS/ Dataset_Documentation/NHIS/2001/ srvydesc.pdf).

62. National Center for Health Statistics. 2002 National Health Interview Survey (NHIS). Public-Use Data Release. NHIS Survey Description (ftp://ftp.cdc.gov/pub/ Health_Statistics/NCHS/ Dataset_Documentation/NHIS/2002/ srvydesc.pdf).

63. National Center for Health Statistics. 2003 National Health Interview Survey (NHIS). Public-Use Data Release. NHIS Survey Description (ftp://ftp.cdc.gov/pub/ Health_Statistics/NCHS/

Dataset_Documentation/NHIS/2003/ srvydesc.pdf).

64. National Center for Health Statistics. 2004 National Health Interview Survey (NHIS). Public-Use Data Release. NHIS Survey Description (ftp://ftp.cdc.gov/pub/ Health_Statistics/NCHS/

Dataset_Documentation/NHIS/2004/ srvydesc_injury.pdf).

65. Day JC. Population projections of the United States by age, sex, race, and Hispanic origin: 1995 to 2050, U.S. Bureau of the Census, Current Population Reports, P25-1130. Washington. U.S. Government Printing Office. 1996. (http:// www.census.gov/prod/1/pop/p251130).

66. Klein RJ, Schoenborn CA. Age adjustment using the 2000 projected U.S. population. Healthy People Statistical Notes, no 20. Hyattsville, MD. National Center for Health Statistics. 2001.

67. Office of Management and Budget. Revisions to the Standards for the Classification of Federal Data on Race and Ethnicity. Federal Register 1997; 62(210):58782-90. 
Table 1. Crude 30-day prevalence rates (with standard errors) of adults with serious psychological distress, by selected sociodemographic characteristics: United States, 2001-04

\begin{tabular}{|c|c|c|}
\hline \multirow[b]{2}{*}{ Characteristic } & \multicolumn{2}{|c|}{ Serious psychological distress ${ }^{1}$} \\
\hline & Percent & $\begin{array}{l}\text { Standard } \\
\text { error }\end{array}$ \\
\hline 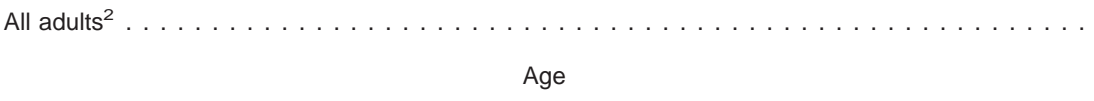 & 3.1 & 0.07 \\
\hline 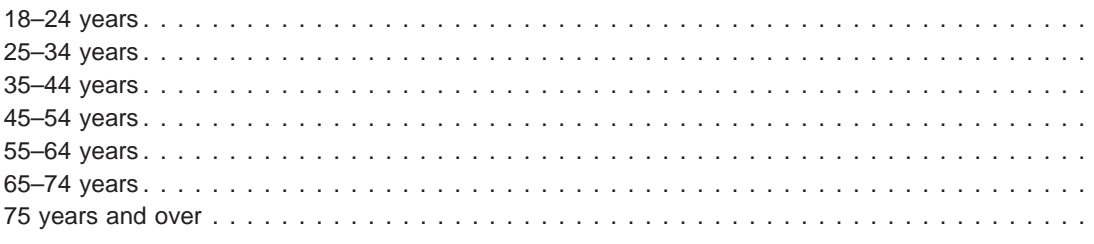 & $\begin{array}{l}2.8 \\
2.6 \\
3.3 \\
4.0 \\
3.6 \\
2.3 \\
2.5\end{array}$ & $\begin{array}{l}0.18 \\
0.11 \\
0.13 \\
0.15 \\
0.17 \\
0.16 \\
0.18\end{array}$ \\
\hline \multicolumn{3}{|l|}{ Sex } \\
\hline 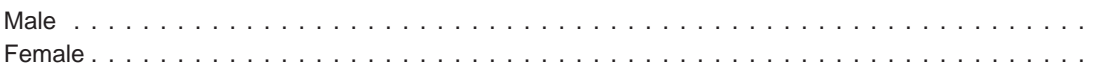 & $\begin{array}{l}2.4 \\
3.9\end{array}$ & $\begin{array}{l}0.08 \\
0.09\end{array}$ \\
\hline \multicolumn{3}{|l|}{ Race and ethnicity } \\
\hline $\begin{array}{l}\text { Hispanic or Latino } \ldots \ldots \ldots \ldots \ldots \ldots \ldots \ldots \ldots \ldots \ldots \ldots \ldots \ldots \ldots \ldots \ldots \ldots \ldots \ldots \ldots \ldots \ldots \ldots \\
\text { Not Hispanic or Latino: }\end{array}$ & 3.5 & 0.15 \\
\hline 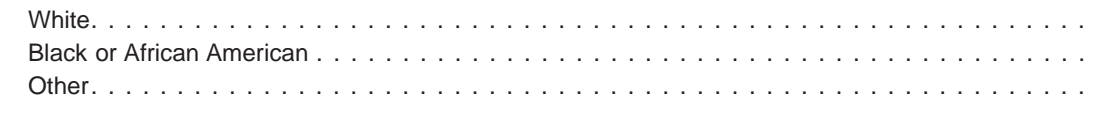 & $\begin{array}{l}3.0 \\
3.5 \\
3.3\end{array}$ & $\begin{array}{l}0.08 \\
0.19 \\
0.29\end{array}$ \\
\hline \multicolumn{3}{|l|}{ Education } \\
\hline 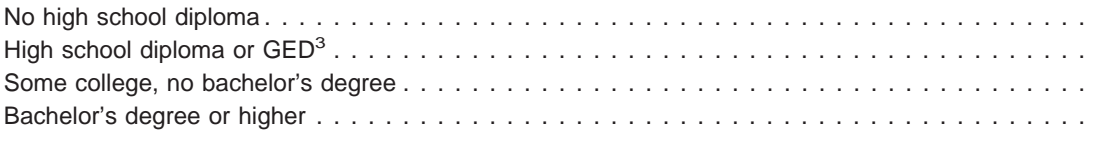 & $\begin{array}{l}6.2 \\
3.3 \\
2.8 \\
1.2\end{array}$ & $\begin{array}{l}0.20 \\
0.12 \\
0.10 \\
0.07\end{array}$ \\
\hline \multicolumn{3}{|l|}{ Poverty status ${ }^{4}$} \\
\hline 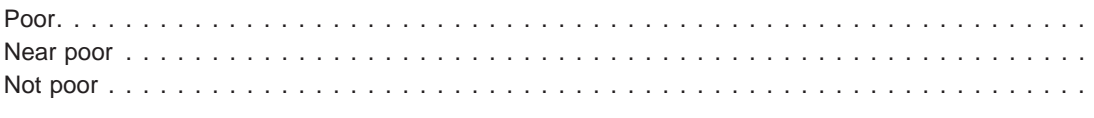 & $\begin{array}{l}8.0 \\
4.8 \\
1.9\end{array}$ & $\begin{array}{l}0.32 \\
0.18 \\
0.06\end{array}$ \\
\hline \multicolumn{3}{|l|}{ Marital status } \\
\hline 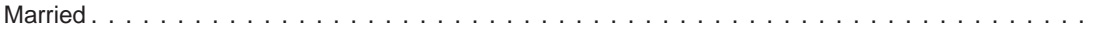 & 2.3 & 0.07 \\
\hline Never married. . . . . . . . . . . . . . . . . . . . . . . . . . . . . & 3.3 & 0.13 \\
\hline 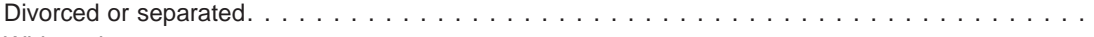 & 6.2 & 0.21 \\
\hline Widowed . . . . . . . . . . . . . . . . . . . . . . . . . . & 4.1 & 0.21 \\
\hline
\end{tabular}

${ }^{1}$ Six psychological distress questions are included in the Sample Adult Core component. These questions ask how often a respondent experienced certain symptoms of psychological distress during the past 30 days. The response code $(0-4)$ of the six items for each person are summed to yield a scale with a $0-24$ range. A value of 13 or more for this scale is used here to define serious psychological distress.

${ }^{2}$ Persons of other races and unknown race and ethnicity, unknown education, unknown family income, unknown poverty level, unknown employment status, and unknown marital status are included in the total but not shown separately.

${ }^{3}$ GED is General Educational Development high school equivalency diploma.

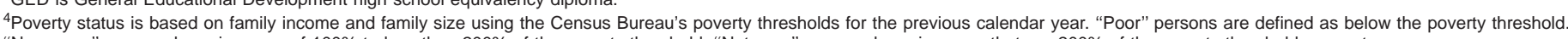
"Near poor" persons have incomes of $100 \%$ to less than $200 \%$ of the poverty threshold. "Not poor" persons have incomes that are $200 \%$ of the poverty threshold or greater. 
Table 2. Age-adjusted percent distributions (with standard errors) of selected sociodemographic characteristics among adults, by presence or absence of serious psychological distress: United States, 2001-04

\begin{tabular}{|c|c|c|c|c|c|}
\hline \multirow[b]{3}{*}{ Characteristic } & \multicolumn{5}{|c|}{ Psychological distress $^{1}$} \\
\hline & \multicolumn{2}{|c|}{$\begin{array}{l}\text { Serious psychological } \\
\text { distress }\end{array}$} & \multicolumn{2}{|c|}{$\begin{array}{l}\text { No serious psychological } \\
\text { distress }\end{array}$} & \multirow[b]{2}{*}{$\begin{array}{c}p- \\
\text { value }\end{array}$} \\
\hline & Percent & $\begin{array}{l}\text { Standard } \\
\text { error }\end{array}$ & Percent & $\begin{array}{l}\text { Standard } \\
\text { error }\end{array}$ & \\
\hline$\ldots \ldots \ldots \ldots \ldots \ldots \ldots \ldots$ & 100.0 & & 100.0 & $\ldots$ & . \\
\hline \multicolumn{6}{|l|}{$\mathrm{Age}^{3}$} \\
\hline $18-44$ years . . . . . . . . . . . . . . . . . . . & 48.7 & 0.91 & 52.5 & 0.27 & $f$ \\
\hline $45-64$ years . . . . . . . . . . . . . . . . . . . & 39.2 & 0.88 & 31.5 & 0.20 & $f$ \\
\hline 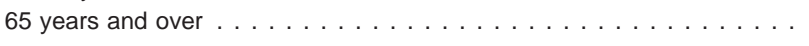 & 12.1 & 0.58 & 16.0 & 0.18 & $f$ \\
\hline \multicolumn{6}{|l|}{ Sex } \\
\hline 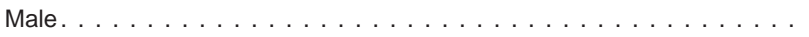 & 35.8 & 0.93 & 48.2 & 0.18 & $f$ \\
\hline 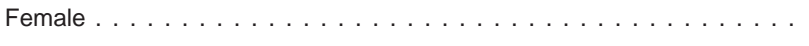 & 64.2 & 0.93 & 51.8 & 0.18 & $f$ \\
\hline \multicolumn{6}{|l|}{ Race and ethnicity } \\
\hline Hispanic or Latino . . . . . . . . . . . . . . . . . . . . . . . . . & 13.7 & 0.62 & 12.0 & 0.20 & - \\
\hline \multicolumn{6}{|l|}{ Not Hispanic or Latino: } \\
\hline White . . . . . . . . . . . . . . . . . . . & 69.1 & 0.92 & 72.1 & 0.33 & $f$ \\
\hline 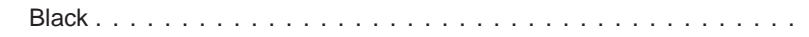 & 12.2 & 0.68 & 10.9 & 0.25 & - \\
\hline 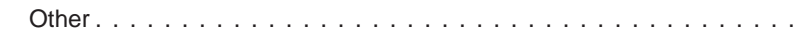 & 5.0 & 0.46 & 4.9 & 0.13 & - \\
\hline \multicolumn{6}{|l|}{ Education } \\
\hline No high school diploma . . . . . . . . . . . . . . . . . . . . . . . & 34.2 & 0.92 & 16.5 & 0.21 & $f$ \\
\hline High school diploma or GED ${ }^{4} \ldots \ldots \ldots \ldots \ldots \ldots$ & 31.3 & 0.87 & 29.4 & 0.22 & - \\
\hline Some college, no bachelors degree $\ldots \ldots \ldots \ldots \ldots \ldots$ & 25.1 & 0.76 & 29.2 & 0.20 & $f$ \\
\hline Bachelor's degree or higher $\ldots \ldots \ldots \ldots \ldots \ldots \ldots$ & 9.4 & 0.53 & 24.8 & 0.27 & $f$ \\
\hline \multicolumn{6}{|l|}{ Family income } \\
\hline 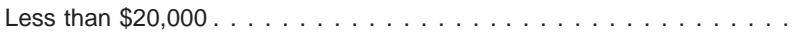 & 44.1 & 1.05 & 19.5 & 0.24 & $f$ \\
\hline 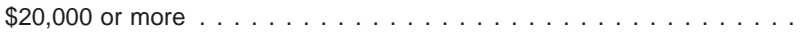 & 55.9 & 1.05 & 80.5 & 0.24 & $f$ \\
\hline 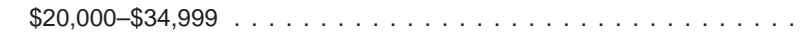 & 23.8 & 0.85 & 19.5 & 0.18 & $f$ \\
\hline 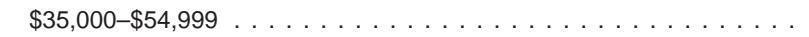 & 15.4 & 0.73 & 20.2 & 0.17 & $f$ \\
\hline 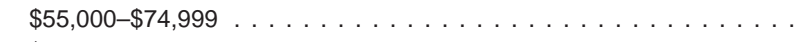 & 7.3 & 0.56 & 14.2 & 0.17 & $f$ \\
\hline 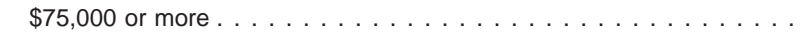 & 9.4 & 0.80 & 26.6 & 0.28 & $f$ \\
\hline \multicolumn{6}{|l|}{ Poverty status ${ }^{5}$} \\
\hline Poor. . . . . . . . . . . . . . . . . . . . . . & 29.2 & 0.96 & 11.2 & 0.19 & $f$ \\
\hline 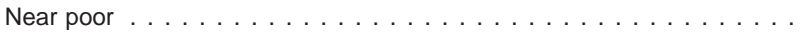 & 28.4 & 0.87 & 17.8 & 0.17 & $f$ \\
\hline 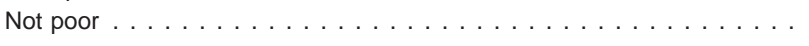 & 42.4 & 1.00 & 71.0 & 0.27 & $f$ \\
\hline \multicolumn{6}{|l|}{ Family size } \\
\hline 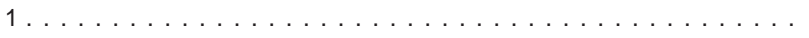 & 23.8 & 0.70 & 18.6 & 0.23 & $f$ \\
\hline 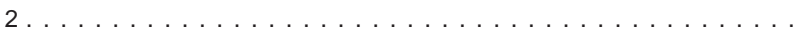 & 30.8 & 0.81 & 33.1 & 0.17 & $f$ \\
\hline 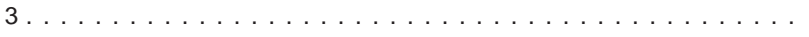 & 18.6 & 0.73 & 18.1 & 0.15 & - \\
\hline 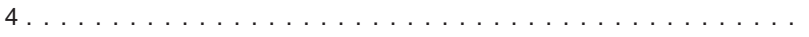 & 13.5 & 0.70 & 17.0 & 0.15 & $f$ \\
\hline 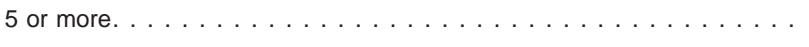 & 13.3 & 0.71 & 13.2 & 0.16 & - \\
\hline \multicolumn{6}{|l|}{ Marital status } \\
\hline Married . . . . . . . . . . . . . . . . . . . . . . . & 41.9 & 0.96 & 58.4 & 0.25 & $f$ \\
\hline 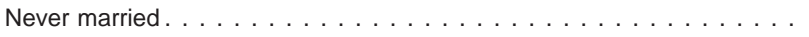 & 24.8 & 0.75 & 22.9 & 0.22 & - \\
\hline Divorced or separated . . . . . . . . . . . . . . . . . . . . . & 23.5 & 0.74 & 12.0 & 0.11 & $f$ \\
\hline Widowed $\ldots \ldots \ldots \ldots \ldots \ldots \ldots \ldots \ldots \ldots \ldots$ & 9.8 & 0.44 & 6.8 & 0.07 & $f$ \\
\hline \multicolumn{6}{|l|}{ Place of residence ${ }^{6}$} \\
\hline 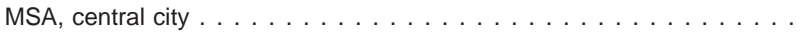 & 29.4 & 1.05 & 27.9 & 0.56 & - \\
\hline MSA, not in central city $\ldots \ldots \ldots \ldots \ldots \ldots \ldots \ldots \ldots \ldots \ldots \ldots \ldots \ldots \ldots \ldots$ & 46.4 & 1.25 & 51.9 & 0.64 & $f$ \\
\hline 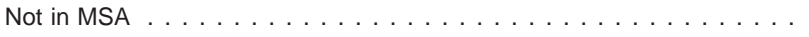 & 24.2 & 1.10 & 20.2 & 0.47 & $f$ \\
\hline
\end{tabular}

Category not applicable.

$f \mathrm{p}<0.01$ for a test of the difference between persons with serious psychologocal distress and no serious psychological distress.

$-p \geq 0.01$ for this test.

${ }^{1}$ Six psychological distress questions are included in the Sample Adult Core component. These questions ask how often a respondent experienced certain symptoms of psychological distress during the past 30 days. The response codes $(0-4)$ of the six items for each person are summed to yield a scale with a $0-24$ range. A value of 13 or more for this scale is used here to define serious psychological distress.

${ }^{2}$ Persons of other races and unknown race and ethnicity, unknown education, unknown family income, unknown poverty level, unknown employment status, and unknown marital status are included in the total but not shown separately.

${ }^{3}$ Estimates for age groups are not age adjusted.

${ }^{4} \mathrm{GED}$ is General Educational Development high school equivalency diploma.

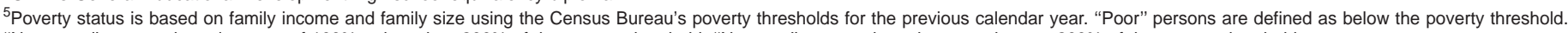
"Near poor" persons have incomes of $100 \%$ to less than $200 \%$ of the poverty threshold. "Not poor" persons have incomes that are $200 \%$ of the poverty threshold or greater.

${ }^{6} \mathrm{MSA}$ is a metropolitan statistical area.

NOTE: Estimates are age adjusted to the 2000 U.S. standard population using five age groups: $18-44$ years, $45-54$ years, 55-64 years, $65-74$ years, and 75 years and over. 
Table 3. Age-adjusted percents (with standard errors) of adults with selected health characteristics, by presence or absence of serious psychological distress: United States, 2001-04

\begin{tabular}{|c|c|c|c|c|c|}
\hline \multirow[b]{3}{*}{ Characteristic } & \multicolumn{5}{|c|}{ Psychological distress ${ }^{1}$} \\
\hline & \multicolumn{2}{|c|}{$\begin{array}{c}\text { Serious psychological } \\
\text { distress }\end{array}$} & \multicolumn{2}{|c|}{$\begin{array}{c}\text { No serious psychological } \\
\text { distress }\end{array}$} & \multirow[b]{2}{*}{$\begin{array}{c}p- \\
\text { value }\end{array}$} \\
\hline & Percent & $\begin{array}{l}\text { Standard } \\
\text { error }\end{array}$ & Percent & $\begin{array}{l}\text { Standard } \\
\text { error }\end{array}$ & \\
\hline \multicolumn{6}{|l|}{ Self-assessed health ${ }^{2}$} \\
\hline 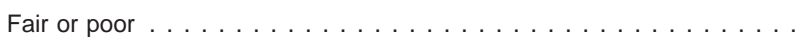 & 49.7 & 0.89 & 10.7 & 0.13 & $f$ \\
\hline \multicolumn{6}{|l|}{ Selected risk factors } \\
\hline \multicolumn{6}{|l|}{$\mathrm{BMl}^{3}$} \\
\hline Underweight (less than 18.5$) \ldots \ldots \ldots \ldots \ldots \ldots$ & 3.6 & 0.37 & 2.0 & 0.05 & $f$ \\
\hline Normal weight $(18.5$ to less than 25.0$) \ldots \ldots \ldots \ldots \ldots \ldots$ & 34.4 & 0.91 & 39.4 & 0.19 & $f$ \\
\hline 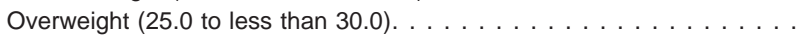 & 28.7 & 0.83 & 35.5 & 0.17 & $f$ \\
\hline Obese (greater than or equal to 30.0$) \ldots \ldots \ldots \ldots \ldots$ & 33.3 & 0.89 & 23.1 & 0.17 & $f$ \\
\hline \multicolumn{6}{|l|}{ Smoker ${ }^{4}$} \\
\hline 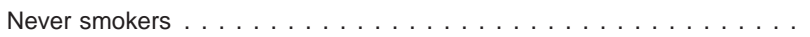 & 37.3 & 0.91 & 56.8 & 0.21 & $f$ \\
\hline 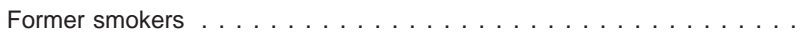 & 20.3 & 0.74 & 22.1 & 0.15 & - \\
\hline 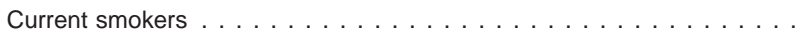 & 42.4 & 0.88 & 21.1 & 0.17 & $f$ \\
\hline \multicolumn{6}{|l|}{ Ever diagnosed with selected chronic diseases } \\
\hline$\ldots \ldots \ldots \ldots \ldots \ldots \ldots$ & 13.0 & 0.58 & 6.4 & 0.08 & $f$ \\
\hline 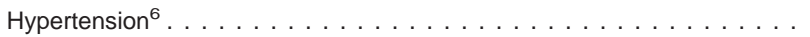 & 39.2 & 0.87 & 24.2 & 0.14 & $f$ \\
\hline 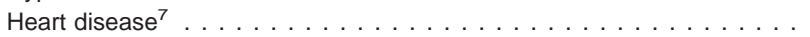 & 14.2 & 0.6 & 7.1 & 0.09 & $f$ \\
\hline 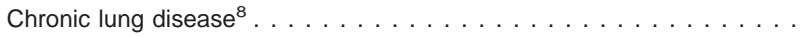 & 24.4 & 0.84 & 10.8 & 0.11 & $f$ \\
\hline 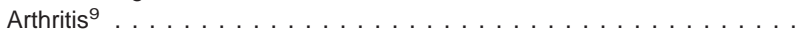 & 40.4 & 0.96 & 20.7 & 0.16 & $f$ \\
\hline 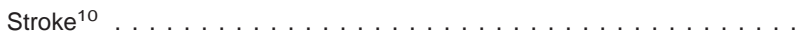 & 7.7 & 0.49 & 2.3 & 0.05 & $f$ \\
\hline 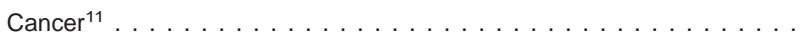 & 10.3 & 0.61 & 6.8 & 0.08 & $f$ \\
\hline \multicolumn{6}{|l|}{ Number of chronic diseases ${ }^{12}$} \\
\hline 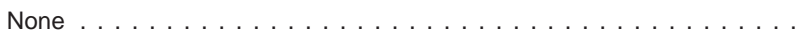 & 38.8 & 0.83 & 60.6 & 0.17 & $f$ \\
\hline 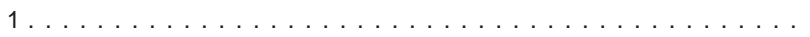 & 26.5 & 0.80 & 23.0 & 0.15 & $f$ \\
\hline 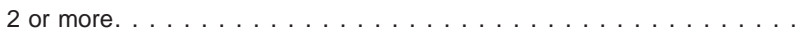 & 34.8 & 0.85 & 16.5 & 0.12 & $f$ \\
\hline
\end{tabular}

$f \mathrm{p}<0.01$ for a test of the difference between persons with serious psychological distress and no serious psychological distress.

$-\mathrm{p} \geq 0.01$ for this test.

${ }^{1}$ Six psychological distress questions are included in the Sample Adult Core component. These questions ask how often a respondent experienced certain symptoms of psychological distress during the past 30 days. The response codes (0-4) of the six items for each person are summed to yield a scale with a 0-24 range. A value of 13 or more for this scale is used here to define serious psychological distress.

${ }^{2}$ Self-assessed health is based on a question in the survey that asked respondents, "Would you say [subject's name] health in general was excellent, very good, good, fair, or poor?" This information was obtained during a part of the interview that allowed proxy responses, such that a knowledgeable adult family member could respond on behalf of adults not taking part in the interview (however, the data above are based on the reported health status for the sample adult only). "Fair" and "poor" are combined.

${ }^{3} \mathrm{BMI}$ is body mass index based on self-reported height and weight.

${ }^{4}$ Smoking status: Never smoker-have never smoked at least 100 cigarettes in their lifetime. Former smoker-have smoked at least 100 cigarettes in their lifetime, but currently do not smoke. Current smoker-have smoked at least 100 cigarettes in their lifetime and still currently smoke.

${ }^{5}$ Respondents were asked if they had ever been told by a doctor or health professional that they have diabetes or sugar diabetes (if female, other than during pregnancy)

${ }^{6}$ Respondents were asked if they had ever been told by a doctor or health professional that they had hypertension.

${ }^{7}$ Heart disease includes coronary heart disease, heart attack, and angina. Respondents were asked if they had ever been told by a doctor or health professional that they had any of these conditions.

${ }^{8}$ Chronic lung disease includes chronic bronchitis and asthma. Respondents were asked if they had ever been told by a doctor or health professional that they had either of these conditions.

${ }^{9}$ Respondents were asked if they had ever been told by a doctor or health professional that they had arthritis.

${ }^{10}$ Respondents were asked if they had ever been told by a doctor or health professional that they had a stroke.

${ }^{11}$ Respondents were asked if they had ever been told by a doctor or health professional that they had cancer or a malignancy of any kind.

${ }^{12}$ The number of chronic diseases is calculated by counting how many of the seven diseases listed above the respondent reported.

NOTE: Estimates are age adjusted to the 2000 U.S. standard population using five age groups: $18-44$ years, $45-54$ years, $55-64$ years, $65-74$ years, and 75 years and over. 
Table 4. Age-adjusted percents (with standard errors) of selected access to care and health care utilization characteristics among adults, by presence or absence of serious psychological distress: United States, 2001-04

\begin{tabular}{|c|c|c|c|c|c|}
\hline \multirow[b]{3}{*}{ Characteristic } & \multicolumn{5}{|c|}{ Psychological distress ${ }^{1}$} \\
\hline & \multicolumn{2}{|c|}{$\begin{array}{c}\text { Serious psychological } \\
\text { distress }\end{array}$} & \multicolumn{2}{|c|}{$\begin{array}{l}\text { No serious psychological } \\
\text { distress }\end{array}$} & \multirow[b]{2}{*}{$\begin{array}{c}p- \\
\text { value }\end{array}$} \\
\hline & Percent & $\begin{array}{l}\text { Standard } \\
\text { error }\end{array}$ & Percent & $\begin{array}{l}\text { Standard } \\
\text { error }\end{array}$ & \\
\hline \multicolumn{6}{|l|}{ Health insurance coverage: ${ }^{2}$} \\
\hline 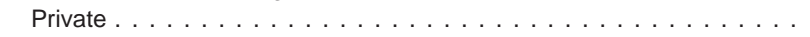 & 38.5 & 1.01 & 73.0 & 0.25 & $f$ \\
\hline Medicaid/other public . . . . . . . . . . . . . . . . . . . . & 25.0 & 0.95 & 5.7 & 0.11 & $f$ \\
\hline 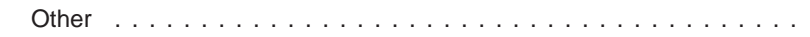 & 7.7 & 0.51 & 2.7 & 0.08 & $f$ \\
\hline 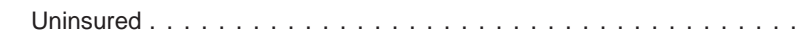 & 28.8 & 0.92 & 18.5 & 0.20 & $f$ \\
\hline 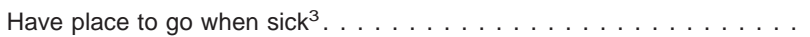 & 82.4 & 0.70 & 85.3 & 0.16 & $f$ \\
\hline \multicolumn{6}{|l|}{ Cannot afford: ${ }^{4}$} \\
\hline 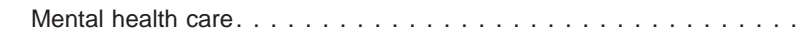 & 18.1 & 0.72 & 1.5 & 0.04 & $f$ \\
\hline 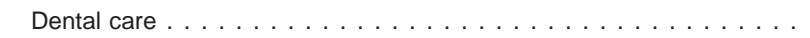 & 32.2 & 0.88 & 9.6 & 0.12 & $f$ \\
\hline 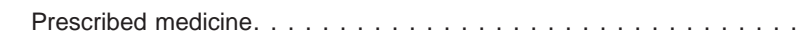 & 31.9 & 0.90 & 6.6 & 0.09 & $f$ \\
\hline \multicolumn{6}{|l|}{ Time since last talked to health professional: ${ }^{5}$} \\
\hline 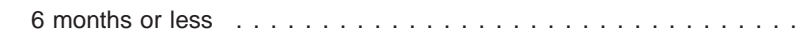 & 80.9 & 0.71 & 68.6 & 0.18 & $f$ \\
\hline More than 6 months but not more than 1 year. $\ldots \ldots \ldots$ & 7.4 & 0.47 & 14.0 & 0.13 & $f$ \\
\hline More than 1 year. $\ldots \ldots \ldots \ldots \ldots \ldots \ldots \ldots \ldots$ & 10.7 & 0.56 & 16.0 & 0.14 & $f$ \\
\hline 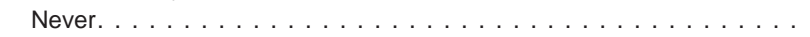 & 1.0 & 0.18 & 1.4 & 0.06 & - \\
\hline \multicolumn{6}{|l|}{ Total number of doctor visits, past 12 months: ${ }^{6}$} \\
\hline 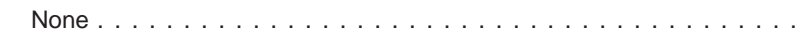 & 13.5 & 0.61 & 19.2 & 0.16 & $f$ \\
\hline 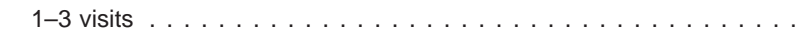 & 22.2 & 0.80 & 43.3 & 0.19 & $f$ \\
\hline 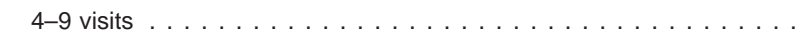 & 25.1 & 0.83 & 24.3 & 0.15 & - \\
\hline 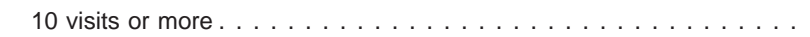 & 39.2 & 0.90 & 13.2 & 0.13 & $f$ \\
\hline Spoken to mental health professional, past 12 months . . . . . . . . . . . & 32.4 & 0.86 & 5.3 & 0.08 & $f$ \\
\hline
\end{tabular}

$f \mathrm{p}<0.01$ for a test of the difference between persons with serious psychological distress and no serious psychological distress.

$-p \geq 0.01$ for this test.

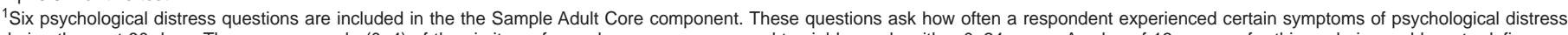
during the past 30 days. The response code $(0-4)$ of the six items for each person are summed to yield a scale with a $0-24$ range. A value of 13 or more for this scale is used here to define serious psychological distress.

${ }^{2}$ Classification of health insurance coverage is based on a hierarchy of mutually exclusive categories. Persons with more than one type of health insurance were assigned to the first appropriate category in the hierarchy. The category "Uninsured" includes persons who had no coverage as well as those who had only Indian Health Service coverage or had only a private plan that paid for one type of service such as accidents or dental care. Health insurance coverage includes person under 65 years of age.

${ }^{3}$ Have place to go when sick is based on a question in the survey that asked, "Is there a place that you usually go to when you are sick or need advice about your health?"

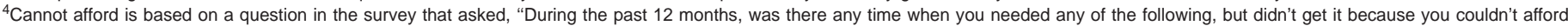
it?": Prescription medicine, Mental health care or counseling, Dental care (including check-ups).

${ }^{5}$ Time since last talked to health professional is based on a question in the survey that asked respondents, "About how long has it been since you saw or talked to a doctor or other health care professional about your own health?" These contacts may include office visits, hospital visits, home visits, and phone calls (but not calls made for arranging appoinments).

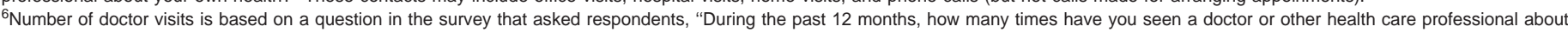

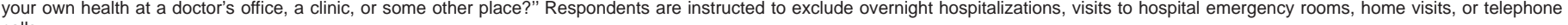
calls.

NOTE: Estimates are age adjusted to the year 2000 projected U.S. population using five age group: $18-44$ years, $45-54$ years, 55-64 years, $65-74$ years, and 75 years and over. 
Table 5. Age-adjusted percents (with standard errors) of adults aged 18 years and over with selected activity limitations and impairments, by presence or absence of serious psychological distress: United States, 2001-04

\begin{tabular}{|c|c|c|c|c|c|}
\hline \multirow[b]{3}{*}{ Characteristic } & \multicolumn{5}{|c|}{ Psychological distress ${ }^{1}$} \\
\hline & \multicolumn{2}{|c|}{$\begin{array}{c}\text { Serious psychological } \\
\text { distress }\end{array}$} & \multicolumn{2}{|c|}{$\begin{array}{l}\text { No serious psychological } \\
\text { distress }\end{array}$} & \multirow[b]{2}{*}{$\begin{array}{c}p- \\
\text { value }\end{array}$} \\
\hline & Percent & $\begin{array}{c}\text { Standard } \\
\text { error }\end{array}$ & Percent & $\begin{array}{l}\text { Standard } \\
\text { error }\end{array}$ & \\
\hline \multicolumn{6}{|l|}{ Impairment } \\
\hline Visual impairment. . . . . . . . . . . . . . . . . . . . . . & 27.4 & 0.86 & 8.6 & 0.11 & $f$ \\
\hline 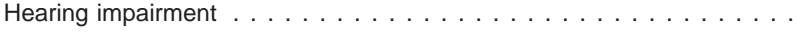 & 8.1 & 0.47 & 3.0 & 0.06 & $f$ \\
\hline \multicolumn{6}{|l|}{ Limitation } \\
\hline Activities of daily living $(A D L)^{2} \ldots$ & 9.8 & 0.52 & 1.4 & 0.04 & $f$ \\
\hline Instrumental activities of daily living $(\text { IADL })^{3} \ldots \ldots \ldots \ldots$ & 19.3 & 0.70 & 3.2 & 0.06 & $f$ \\
\hline \multicolumn{6}{|l|}{ Physical limitations } \\
\hline 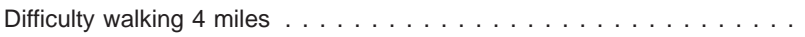 & 41.1 & 0.87 & 9.7 & 0.11 & $f$ \\
\hline Difficulty walking up 10 steps $\ldots \ldots \ldots \ldots \ldots \ldots$ & 35.3 & 0.86 & 7.3 & 0.10 & $f$ \\
\hline \multicolumn{6}{|l|}{ Impairments in social functioning } \\
\hline Going out shopping, to movies, to sporting events ${ }^{4}$. & 33.7 & 0.91 & 4.9 & 0.08 & $f$ \\
\hline Visiting friends, going to clubs, meetings, or parties ${ }^{5} \ldots \ldots \ldots$ & 31.8 & 0.90 & 3.7 & 0.07 & $f$ \\
\hline Relaxing at home, reading, watching TV, sewing, or listening to music ${ }^{6}$. & 17.9 & 0.73 & 1.6 & 0.05 & $f$ \\
\hline
\end{tabular}

$f \mathrm{p}<0.01$ for a test of the difference between persons with serious psychological distress and no serious psychological distress.

$-p \geq 0.01$ for this test.

${ }^{1}$ Six psychological distress questions are included in the Sample Adult Core component. These questions ask how often a respondent experienced certain symptoms of psychological distress during the past 30 days. The response code (0-4) of the six items for each person are summed to yield a scale with a $0-24$ range. A value of 13 or more for this scale is used here to define serious psychological distress.

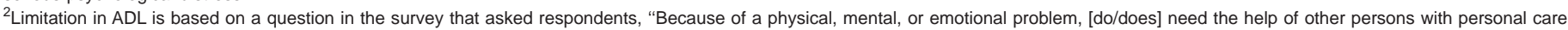
needs, such as eating, bathing, dressing, or getting around inside the home?"

${ }^{3}$ Limitation in IADL is based on a question in the survey that asked respondents, "Because of a physical, mental, or emotional problem, [do/does] [person] need the help of other persons in handling routine needs, such as everyday household chores, doing necessary business, shopping, or getting around for other purposes?"

${ }^{4}$ Respondents were asked, "By yourself, and without using any special equipment, how difficult is it for you to: Go out to things like shopping, movies, or sporting events?"

${ }^{5}$ Respondents were asked, "How difficult is it for you to: Participate in social activities such as visiting friends, attending clubs and meetings, going to parties. ..?"

${ }^{6}$ Respondents were asked, "How difficult is it for you to: do things to relax at home or for leisure (reading, watching TV, sewing, listening to music)?"

NOTE: Estimates are age adjusted to the year 2000 projected U.S. population using five age group: $18-44$ years, $45-54$ years, 55-64 years, $65-74$ years, and 75 years and over. 


\section{Technical Notes}

\section{Sample design}

The National Health Interview Survey (NHIS) is a cross-sectional household interview survey of the U.S. civilian noninstitutionalized population. Data are collected continuously throughout the year in all 50 States and the District of Columbia. The NHIS uses a multistage, clustered sample design. Information on basic health topics is collected for all household members, by proxy from one family member for adults not present at the time of interview and by proxy for children. Additional information is collected for one randomly sampled adult (the "sample adult") and one randomly sampled child (the "sample child") in each family with at least one child. Self-response is required for the Sample Adult questionnaire except in the case of sample adults who are physically or mentally incapable of responding for themselves. An adult family member who is knowledgeable about the sample child's health provides information for the child component. Interviews are conducted in the home using a computer-assisted personal interview (CAPI) questionnaire. Telephone follow-up is permitted to complete the survey after the initial home interview if a further in-home interview cannot be done.

\section{Response rates}

Combining years 2001-04, NHIS interviews were completed for 147,593 households and 150,503 families, with 126,548 adults aged 18 years and over completing the Sample Adult questionnaire. The final response rate for the 2001-04 combined household files was $88.6 \%$ and for sample adult files was $73.7 \%$. Procedures used in calculating response rates for combined data years are described in detail in Appendix I of the Survey Description of the NHIS data files (61-64). The number of completed household, family, and sample adult interviews by year and household and sample adult response rates by year are presented in table I.

Table I. Completed interviews and response rates by year and for the $\mathbf{4}$ years combined: National Health Interview Survey, 2001-04

\begin{tabular}{|c|c|c|c|c|c|}
\hline Interviews and rates & 2001 & 2002 & 2003 & 2004 & $2001-04$ \\
\hline Completed interviews & \multicolumn{5}{|c|}{ Number in thousands } \\
\hline Household . . . . & 38,932 & 36,161 & 35,921 & 36,579 & 147,593 \\
\hline$\ldots \ldots \ldots$ & 39,633 & 36,831 & 36,573 & 37,466 & 150,503 \\
\hline Sample adult $\ldots \ldots \ldots \ldots \ldots$ & 33,326 & 31,044 & 30,852 & 31,326 & 126,548 \\
\hline Response rate & \multicolumn{5}{|c|}{ Percent } \\
\hline Household . . . . . . . . . . . . . & 88.9 & 89.6 & 89.2 & 86.9 & 88.6 \\
\hline Sample adult . . . . . . . . . . . . & 73.8 & 74.3 & 74.2 & 72.5 & 73.7 \\
\hline
\end{tabular}

\section{Age adjustment and significance tests}

Data shown in this report were age adjusted using the 2000 projected U.S. population (65-66). Age adjustment was used to allow comparison among population subgroups that have different age structures. The following age groups were used for age adjustment: 18-44 years, $45-54$ years, 55-64 years, 65-74 years, and 75 years and over.

Estimates were calculated using software for statistical analysis of correlated data (SUDAAN) (23). The SUDAAN procedure PROC DESCRIPT was used to produce age-adjusted percents and their standard errors.

Statistical tests performed to assess the significance of differences between estimates were two-tailed with no formal adjustment for multiple comparisons. The test statistic used to determine statistical significance of the difference between two percents was:

$$
\mathrm{Z}=\frac{\left|\mathrm{X}_{a}-\mathrm{X}_{\mathrm{b}}\right|}{\sqrt{\mathrm{S}_{a}{ }^{2}+\mathrm{S}_{b}{ }^{2}}} .
$$

Here $X_{a}$ and $X_{b}$ are the two percents being compared, and $S_{a}$ and $S_{b}$ are the SUDAAN-calculated standard errors of the percents. The critical value used for two-sided tests at the 0.01 level was 2.58 .

\section{Relative standard error}

Estimates with a relative standard error greater than $30 \%$ are considered unreliable. The relative standard errors are calculated as follows: Relative standard error $=(\mathrm{SE} / \mathrm{Est}) 100$, where SE is the standard error of the estimate, and Est is the estimate (percent, rate, mean, or frequency). All estimates presented in this report have a relative standard error less than $30 \%$.

\section{Definitions of selected terms}

\section{Sociodemographic terms}

Age-The age recorded for each adult is the age at the last birthday. Age is recorded in single years and grouped using a variety of age categories depending on the purpose of the table.

Education-The categories of education are based on the years of school completed or highest degree obtained for persons aged 25 and over. Only years completed in a school that advances a person toward an elementary or high school diploma, General Educational Development high school equivalency diploma (GED), college, university, or professional degree are included. Education in other schools and home schooling are counted only if the credits are accepted in a regular school system.

Family income-Each member of a family is classified according to the total income of all family members. Family members are all persons within the household related to each other by blood, marriage, cohabitation, or adoption. The income recorded is the total income received by all family members in the previous calendar year. Income from all sources includes wages, salaries, military pay (when an armed forces member lived in the family), pensions, government payments, child support/alimony, dividends, and help from relatives. Unrelated individuals living in the same household (for example, roommates) are considered to be separate families and are classified according to their own incomes. 
Health insurance coverage-NHIS respondents were asked about their health insurance coverage at the time of the interview. Respondents reported whether they were covered by private insurance (obtained from their employer or workplace, purchased directly, or through a local or community program), Medicare, Medigap (supplemental Medicare coverage), Medicaid, State Children's Health Insurance Plan (SCHIP), Indian Health Service (IHS), military coverage (including VA, TRICARE, or CHAMP-VA), a Statesponsored health plan, another government program and/or single service plans. This information was used to form a health insurance hierarchy for persons under age 65 years.

For persons under 65 years of age, a health insurance hierarchy of four categories was developed. Persons with more than one type of health insurance were assigned to the first appropriate category in the hierarchy listed below:

- Private coverage-Includes persons who had any comprehensive private insurance plan (including health maintenance organizations and preferred provider organizations). These plans include those obtained through an employer, purchased directly, or through local or community programs.

- Medicaid-Includes persons who do not have private coverage, but who have Medicaid and/or other Statesponsored health plans including SCHIP.

- Other coverage-Includes persons who do not have private insurance or Medicaid (other public coverage), but who have any type of military health plan (includes VA, TRICARE, and CHAMP-VA) or Medicare. This category also includes persons who are covered by other government programs.

- Uninsured-Includes persons who have not indicated that they are covered at the time of the interview under private health insurance (from employer or workplace, purchased directly, or through a State, local government, or community program), Medicare, Medicaid, SCHIP, a State-sponsored health plan, other government programs, or military health plan (includes VA, TRICARE, and CHAMP-VA). This category also includes persons who are only covered by IHS or only have a plan that pays for one type of service such as accidents or dental care.

Weighted frequencies indicate that less than $1 \%$ of the adult population under 65 years of age was "unknown" on health insurance.

Marital status-Respondents were asked to choose a marital status category. Adults could select the category they felt most appropriate for their marital situation. A legally annulled marriage is considered as not having taken place. Marital status is classified into the following four categories:

- Married-This category includes all persons who identify themselves as married and who are not separated from their spouses. Married persons living apart because of circumstances of their employment are considered married. Persons may identify themselves as married regardless of the legal status of the marriage or sex of the spouses.

- Separated and divorced-This category includes persons who are legally separated from their spouse or living apart for reasons of marital discord, and those who are divorced.

- Widowed-This category includes persons who have lost their spouse due to death.

- Never married-This category includes persons who were never married.

Place of residence-Place of residence in NHIS is classified as either inside a metropolitan statistical area (MSA) or outside an MSA. Place of residence inside an MSA is further subdivided as either central city or not central city. Generally, an MSA consists of a county or group of counties containing at least one city (or twin cities) having a population of 50,000 or more plus adjacent counties that are metropolitan in character and economically and socially integrated with the central city. In New England, towns and cities rather than counties are the units used in defining MSAs. There is no limit to the number of adjacent counties included in the MSA if they are integrated with the central city, nor is an MSA limited to a single State; MSA boundaries may cross State lines. Central city includes the largest city in a metropolitan statistical area. One or two additional cities may be secondary central cities on the basis of either of the following criteria: (a) the additional city or cities must have a population one-third or more of that of the largest city and a minimum population of 25,000 , or (b) the additional city or cities must have at least 250,000 inhabitants. Noncentral city includes all of the MSA that is not part of the central city itself. Not MSA refers to persons not living in an MSA.

Poverty status-Poverty status is based on family income and family size using the Census Bureau's poverty thresholds. "Poor" persons are defined as persons whose family incomes are below the poverty threshold. "Near poor" persons have family incomes of $100 \%$ to less than $200 \%$ of the poverty threshold. "Not poor" persons have family incomes that are $200 \%$ of the poverty threshold or greater.

Race-In this report, race and ethnicity consists of four categories: not Hispanic white, not Hispanic black or African American, not Hispanic other and Hispanic. Persons in these categories are all single-race persons, in accordance with the 1997 Office of Management and Budget (OMB) federal guidelines (67). Prior to 2003, "Other race" was a separate race response on the NHIS. In the 2003 NHIS, however, editing procedures were changed to maintain consistency with the U.S. Census Bureau procedures for collecting and editing data on race and ethnicity. As a result of these changes, in cases where "Other race" was mentioned along with one or more OMB race groups, the "Other race" response is dropped, and the OMB race group information is retained on the NHIS data file. In cases where "Other race" was the only race response, it is treated as missing and the race is imputed. Although this change has resulted in an increase in the number of persons in the OMB race category "White" because 
this is numerically the largest group, the change is not expected to have a substantial effect on the estimates in this report which categorizes persons by race and ethnicity. Individuals who report Hispanic ethnicity are categorized as Hispanic regardless of their reported race. The vast majority of persons reporting "other race" are Hispanics. More information about the race and ethnicity editing procedures used by the U.S. Census Bureau can be found at the following web site: http:// www.census.gov/popest/archives/files/ MRSF-01-US1.html.

The text in this report uses shorter versions of the new OMB race terms for conciseness and the tables use the complete terms. For example, the category "Black or African American, single race" in the tables is referred to as "Black" in the text.

\section{Terms related to health characteristics and outcomes}

Health status-Respondent-assessed health status is obtained from a question in the survey that asked respondents, "Would you say your health in general was excellent, very good, good, fair, or poor?" Information was obtained about all respondents, with proxy responses allowed for adults not taking part in the interview.

Body mass index-Body mass index (BMI) is calculated from the sample adult's responses to survey questions regarding height and weight. $\mathrm{BMI}=$ Weight (in $\mathrm{kg}$ )/[Height (in $\mathrm{m}^{2}$ )]. The category Underweight is defined as a BMI less than 18.5. Healthy weight is defined as a BMI greater than or equal to 18.5 and less than 25.0. Overweight is defined as a BMI greater than or equal to 25.0 and less than 30.0. Obese is defined as a BMI greater than or equal to 30.0 .

\section{Cigarette smoking status-}

Information on cigarette smoking status at the time of interview is derived from two questions on the survey. All respondents are first asked, "Have you smoked at least 100 cigarettes in your entire life?" Respondents who answered "yes" to the previous question are then asked, "Do you now smoke cigarettes every day, some days, or not at all?'
- Current smoker-There are two categories of current smokers. Persons in the first category smoke every day, and persons in the second category smoke only on some days.

- Former smoker-This category includes persons who have smoked at least 100 cigarettes in their lifetime, but currently do not smoke at all.

- Never smoker-This category includes persons who have never smoked at least 100 cigarettes in their lifetime.

Doctor or other health professional-Doctor refers to medical doctors (MDs) and osteopathic physicians (DOs), including general practitioners and all types of specialists (such as surgeons, internists, gynecologists, obstetricians, proctologists, psychiatrists, dermatologists, and ophthalmologists). Other health care professional includes physician assistants, psychologists, nurses, physical therapists, chiropractors, etc.

Number of visits to a doctor or other health professional in the past 12 months-This is the number of visits to a doctor's office, clinic, or other place that the respondent has made in the past 12 months regarding their own personal health. Overnight hospital stays, hospital emergency room visits, home visits, and telephone calls are excluded.

Time since last physician or other health care professional contact-This is the length of time, prior to the week of interview, since the respondent last consulted a physician or other health care professional in person or by telephone for health treatment or advice of any type. This may include a contact while a patient is in the hospital as well as a contact from a home visit. The information for the time since the sample adult last had contact with a physician or other health care professional is obtained from two questions-one from the Family Core and one from the Sample Adult Core. In the Family Core the family respondent is shown a calendar detailing the 2 weeks before the interview week and is then asked the following question: "During those 2 weeks, did you see a doctor or other health professional at a doctor's office, a clinic, an emergency room, or some other place?" In the Sample Adult Core, the respondent is asked: "About how long has it been since you saw or talked to a doctor or other health professional about your own health?" The response categories for this sample adult question are: "6 months or less," "more than 6 months, but not more than 1 year ago," "more than 1 year, but not more than 2 years ago," "more than 2 years, but not more than 5 years ago," "more than 5 years ago," and "never." If the answer to the Family Core question is "yes," and if the person to whom the question refers is the sample adult, then the Sample Adult Core question is not asked; rather, an implied response to the Sample Adult Core question of " 6 months or less" is recorded. If the family respondent and the sample adult were not the same person, and an answer of "yes" was given to the Family Core question, then the " 6 months or less" implied response to the Sample Adult question is proxy reported (which occurs for approximately $4 \%$ of sample adults).

Usual place of health care-Usual place of health care was based on a question that asked whether respondents had a place that they usually went to when they were sick or needed advice about their health. If yes, they were asked "What kind of place $\{$ is it/do you go to most often \}- a clinic, a doctor's office, an emergency room, or some other place?" The choices for this second question are: "clinic or health center," "doctor's office or HMO," "hospital emergency room," "hospital outpatient department," "some other place," or "doesn't go to one place most often." Although "hospital emergency room" is not considered a "usual place of health care" in other publications, in this report it is. Also in this report, persons who respond "doesn't go to one place most often" are considered to have a place to go when sick.

Visual impairment-Persons with visual impairment are blind in one or both eyes or report "trouble seeing, even when wearing glasses or contact lenses." 
Hearing impairment-Persons with hearing impairment describe their hearing without a hearing aid as "a lot of trouble" or "deaf."

Limitation in ADL or IADLLimitation in ADL is based on a question in the survey that asked respondents, "Because of a physical, mental, or emotional problem, [do/does] [person] need the help of other persons with personal care needs, such as eating, bathing, dressing, or getting around inside the home?" Limitation in IADL is based on a question in the survey that asked respondents, "Because of a physical, mental, or emotional problem, [do/does] [person] need the help of other persons in handling routine needs, such as everyday household chores, doing necessary business, shopping, or getting around for other purposes?"

Physical limitations-Respondents were asked, "By yourself, and without using any special equipment, how difficult is it for you to ...

Walk a quarter of a mile- about three city blocks?

Walk up 10 steps without resting?

The response categories were "not at all difficult," "only a little difficult," "somewhat difficult," "very difficult," and "can't do at all." Respondents were considered limited if they answered "somewhat" or "very difficult" or "can't do at all."

Impairments in social functioningRespondents were asked, "By yourself, and without using any special equipment, how difficult is it for you to ...

Go out to things like shopping, movies, or sporting events?

Participate in social activities such as visiting friends, attending clubs and meetings, going to parties ...?

Do things to relax at home or for leisure (reading, watching TV, sewing, listening to music ...)?

The response categories were "not at all difficult," "only a little difficult," "somewhat difficult," "very difficult,", and "can't do at all." Respondents were considered limited if they answered "somewhat" or "very difficult" or "can't do at all." 


\section{Suggested citation}

Pratt LA, Dey AN, Cohen AJ. Characteristics of adults with serious psychological distress as measured by the K6 scale: United States, 2001-04. Advance data from vital and heatlh statistics; no 382. Hyattsville, MD: National Center for Health Statistics. 2007.

\section{Copyright information}

All material appearing in this report is in the public domain and may be reproduced or copied without permission; citation as to source, however, is appreciated.
National Center for Health Statistics

Director

Edward J. Sondik, Ph.D.

Acting Co-Deputy Directors Jennifer H. Madans, Ph.D. Michael H. Sadagursky

\section{U.S. DEPARTMENT OF HEALTH \& HUMAN SERVICES}

Centers for Disease Control and Prevention National Center for Health Statistics

3311 Toledo Road

Hyattsville, MD 20782

OFFICIAL BUSINESS

PENALTY FOR PRIVATE USE, $\$ 300$

To receive this publication regularly, contact the National Center for Health Statistics by calling 1-866-441-NCHS (6247)

E-mail: nchsquery@cdc.gov

Internet: www.cdc.gov/nchs

07-0022 (3/07)

CS1094243

T27656

DHHS Publication No. (PHS) 2007-1250 